- Estudi -

\title{
TÉCNICAS PREVENTIVAS DE PROTECCIÓN AMBIENTAL Y NORMATIVA DE SERVICIOS. ANÁLISIS PARTICULARIZADO DE LA EVALUACIÓN DE IMPACTO AMBIENTAL Y DE LA ORDENACIÓN ADMINISTRATIVA DE LA GESTIÓN DE RESIDUOS
}

\author{
J. JOSÉ PERNAS GARCÍA \\ Profesor titular de Derecho administrativo \\ Universidade da Coruña \\ jpernasg@udc.es
}

Recibido: 8 de noviembre de 2010 / Aceptado: 10 de diciembre de 2010

RESUMEN: El objetivo de este trabajo es ahondar en la incidencia de la normativa de servicios en los regímenes de evaluación de impacto ambiental y de intervención administrativa de los operadores e instalaciones de gestión de residuos. Son dos ámbitos, dos "piedras de toque", que nos permiten valorar el impacto efectivo de la normativa de servicios en las técnicas preventivas de protección ambiental. Centrar la cuestión en estos dos regímenes nos permite analizar algunas cuestiones de especial interés, como el avance de los regímenes sustantivos de comunicación y su incidencia en el procedimiento de evaluación de impacto ambiental o el efecto de los límites temporales y territoriales de la Directiva de servicios en la normativa de residuos.

RESUM: L'objectiu d'aquest treball és aprofundir en la incidència de la normativa de serveis en els règims d'avaluació d'impacte ambiental i d'intervenció administrativa dels operadors i instal·lacions de gestió de residus. Són dos àmbits particularment transparents per veure l'impacte efectiu de la normativa de serveis en les tècniques preventives de protecció ambiental. Centrar la qüestió en aquest dos règims ens permet analitzar algunes qüestions d'interès especial, com l'avanç dels règims substantius de 
comunicació i la seva incidència en el procediment d'avaluació d'impacte ambiental o l'efecte dels límits temporals i territorials de la Directiva de serveis en la normativa de residus.

ABSTRACT: The aim of this paper is to analyze the impact of service regulations in the systems of environmental impact assessment and administrative intervention in the management of waste. These are two areas that allow us to assess the actual impact of the rules of services regulation in preventive techniques of environmental protection. To focus the question in these two regimes is a way to analyze some issues of particular interest, as the advance of notification schemes and their impact on the process of environmental impact assessment or the effect of temporal and territorial limits of the services Directive in waste regulation.

PALABRAS CLAVE: Directiva de servicios — "ley ómnibus" — Ley 6/2010 — evaluación de impacto ambiental — gestión de residuos

PARAULES CLAU: Directiva de serveis — "llei òmnibus" — Llei 6/2010 — avaluació d'impacte ambiental — gestió de residus

KEYWORDS: Services Directive — “ómnibus" Act — Act 6/2010 — environmental impact assessment — waste management.

Sumario. I. Introducción. II. Análisis y reflexiones en torno a la articulación del procedimiento de EIA con las técnicas de comunicación previa o declaración responsable: 1 . Consideraciones generales; 2 . La ampliación del concepto "básico" de órgano sustantivo para integrar al órgano competente "para controlar la actividad a través de la declaración responsable o comunicación de los proyectos"; 3 . La naturaleza de la DIA en el caso de proyectos sometidos a obligación sustantiva de comunicación o declaración responsable ante la AGE; 4. El órgano competente "para controlar la actividad a través de la declaración responsable o comunicación" como impulsor del procedimiento de evaluación de impacto ambiental; 5. La distribución de competencias ejecutivas en materia de evaluación de impacto ambiental con relación a los proyectos sometidos a la exigencia de comunicación o declaración responsable; 6. La relación temporal entre el procedimiento de evaluación de impacto ambiental y el cumplimiento de la obligación de comunicación o declaración responsable; 7. La publicación de las decisiones "que se deriven de proyectos sometidos a comunicación o declaración responsable"; 8. La coordinación del procedimiento de autorización ambiental integrada con la evaluación de impacto ambiental y las técnicas de comunicación o declaración responsable; 9. Propuesta de lege ferenda para, según los casos, integrar el procedimiento de evaluación de impacto ambiental o convertirlo en un procedimiento autónomo y decisorio en función de la diversa naturaleza de los proyectos. III. La repercusión de la normativa de servicios en la ordenación de las actividades e instalaciones de gestión de residuos: 1. Consideraciones 
previas; 2. El régimen de intervención administrativa en materia de gestión de residuos: 2.1 Consideraciones generales; 2.2. La vigencia temporal de las autorizaciones de valorización o eliminación y la posibilidad de establecer límites temporales de acuerdo con la normativa de servicios; 2.3. La validez de las autorizaciones de las personas físicas o jurídicas que realizan actividades de valorización o eliminación en todo el territorio nacional; 2.4. La exigencia de comunicación previa a los gestores de residuos no peligrosos; 2.5. La conversión de las obligaciones de inscripción de los gestores de residuos en deberes de registro de oficio por parte de los órganos administrativos. La creación del nuevo "Registro de Producción y Gestión de Residuos del Estado".

\section{INTRODUCCIÓN}

La Directiva 2006/123/CE, de 12 de diciembre, relativa a los servicios del mercado interior tiene como objetivo reducir las trabas injustificadas o desproporcionadas al acceso y ejercicio de las actividades de servicios. La Directiva ha sido transpuesta por la Ley 17/2009, de 23 de noviembre, sobre libre acceso a las actividades de servicios y su ejercicio (en adelante "Ley Paraguas"). Esta norma limita la introducción de restricciones al funcionamiento de los mercados de servicios que no resulten justificadas o proporcionadas.

La "Ley Paraguas" abre un proceso de revisión de las normas de carácter legal y reglamentario, para conseguir el objetivo del libre acceso a los servicios en el territorio nacional y su ejercicio. Se pretende sustituir el control ex ante o a priori de la actividad, que implica la exigencia de autorización previa, por un control ex post o a posteriori de la misma, a partir de la realización de una comunicación o una declaración responsable ${ }^{1}$, cuando aquel resulte injustificado o desproporcionado. Esto supone un cambio de paradigma de profundo calado en el control administrativo de las actividades económicas ${ }^{2}$.

Este proceso de revisión afectó inicialmente a las normas con rango de Ley. Así, la Ley 25/2009, de 22 de diciembre (denominada "Ley ómnibus"), ha modificado diversas leyes, horizontales y sectoriales, para su adaptación a la "Ley Paraguas". Entre ellas algunas en materia ambiental ${ }^{3}$, como la Ley 10/1998, de 21 de abril, de residuos. Ello ha

1 MINISTERIO DE ECONOMÍA Y HACIENDA, Informe sobre la transposición de la Directiva de servicios, 29 de abril de 2010, p. 3.

2 MUÑOZ MACHADO, S., "Ilusiones y conflictos derivados de la Directiva de servicios", Revista General de Derecho Administrativo, núm. 21, 2009, p. 2.

3 La "Ley Ómnibus" ha eliminado regímenes de autorización y requisitos prohibidos de carácter discriminatorio, así como limitaciones territoriales y temporales a la vigencia de las autorizaciones. Ha insertado, asimismo, el régimen de concurrencia en la concesión de autorizaciones cuando se hace uso del dominio público. 
supuesto la adaptación del régimen de ordenación administrativa de las actividades de gestión de residuos, que ha integrado, entre otras cuestiones, las limitaciones territoriales y temporales establecidas por la Directiva de servicios. Por otra parte, la revista de las normas reglamentarias, para su adaptación a la "Ley Paraguas", ha sido llevada a cabo por sectores. En materia ambiental el Real Decreto 367/2010, de 26 de marzo, ha modificado toda una serie de normas ambientales de diferentes ámbitos, entre las que se encuentran los reglamentos que regulan los residuos peligrosos y especiales.

Fuera de este proceso general de revisión iniciado por la normativa de servicios, el Real Decreto Legislativo 1/2008, de 11 de enero, por el que se aprueba el texto refundido de la Ley de Evaluación de Impacto Ambiental de Proyectos (en adelante TRLEIAP) ha sido modificado por una norma específica, la Ley 6/2010, de 24 de marzo, para articular el procedimiento de EIA con los regímenes de comunicación previa o declaración responsable.

El objetivo de este artículo no es analizar, con carácter general, el impacto de la normativa de servicios en el Derecho ambiental, ya que es una cuestión que hemos llevado a cabo en un estudio previo ${ }^{4}$. Nuestro objetivo ahora es ahondar en la incidencia de la normativa de servicios en los regímenes de evaluación de impacto ambiental y de intervención administrativa en materia de gestión de residuos. Hemos elegido estos dos ámbitos como "piedra de toque" para valorar el impacto efectivo de la normativa de servicios en las técnicas preventivas de protección ambiental, ya que ello no permite abordar algunas cuestiones de especial interés.

\footnotetext{
4 "La incidencia de la normativa de servicios en el Derecho ambiental", versión escrita y extendida de la ponencia pronunciada en el Seminario Internacional sobre Prestación de Servizos e Dereito, dirigido por la profesora Alba Nogueria López y celebrado los días 4 y 5 de octubre de 2010 (pendiente de publicación).
} 


\section{ANÁLISIS Y REFLEXIONES EN TORNO A LA ARTICULACIÓN DEL PROCEDIMIENTO DE EIA CON LAS TÉCNICAS DE COMUNICACIÓN PREVIA O DECLARACIÓN RESPONSABLE}

\section{Consideraciones generales}

El TRLEIAP ha sido modificado por la Ley $6 / 2010$, de 24 de $^{2}$ arzo ${ }^{5}$, que ha afectado fundamentalmente al procedimiento de evaluación de proyectos de competencia estatal, si bien algunas de sus previsiones tienen carácter básico.

Con esta modificación se ha pretendido que la evaluación de impacto ambiental (en adelante EIA) sea un medio más eficaz y ágil "para atender a las exigencias de la actividad económica", así como incrementar la transparencia de la actividad administrativa (Exposición de motivos, Ley 6/2010). Asimismo, la Ley 6/2010 ha adaptado el procedimiento de EIA a las nuevas previsiones introducidas en la normativa sectorial sustantiva por la normativa sobre libre acceso a las actividades de servicios, fundamentalmente la mayor presencia del régimen de comunicación previa o declaración responsable como requisito para el acceso a las actividades de servicios.

Esta modificación ha clarificado el procedimiento y reducido y adecuado el plazo de ejecución del procedimiento, con la finalidad de que este instrumento de prevención ambiental sea también un "instrumento facilitador de la actividad económica y social" (Exposición de motivos) ${ }^{6}$. La regulación de la EIA es ahora algo más clara y comprensible. No obstante, esta régimen sigue lastrado de ciertos artificios innecesarios, como la división en fases que dificultan la comprensión del desarrollo del procedimiento. Por otra parte, la regulación de los plazos es algo confusa e incoherente

\footnotetext{
5 Véase un análisis amplio y exhaustivo sobre la reforma en RAZQUIN LIZARRAGA, J. J., "La modificación del texto refundido de la Ley de evaluación de impacto ambiental de proyectos por la Ley 6/2010, de 24 de marzo", Revista Catalana de Dret Ambiental, vol. I, núm. 1, 2010.

6 De acuerdo con este mismo planteamiento, la Ley 6/2009, de 17 de noviembre, sobre medidas ambientales para impulsar las inversiones y la actividad económica de las Illes Balears ha modificado la Ley 11/2006, de 14 de septiembre, de evaluaciones de impacto ambiental y evaluaciones ambientales estratégicas de las Illes Balears. La modificación ha sido adoptada “(...) bajo la idea de clarificar y subrayar la corresponsabilidad de los distintos órganos administrativos y agentes que intervienen en los procedimientos de evaluaciones ambientales, introduciendo plazos cuando no estaban previstos, reduciéndose respecto de los contemplados en la Ley (...)". Con esta revisión “(...) se pretende dar un mayor celeridad a los proyectos, las actividades, los planes y los programas, que son un instrumento para impulsar las inversiones y la actividad económica en las Illes Balears" (Exposición de motivos, ap. II).
} 
en algunos puntos ${ }^{7}$. Si bien el resultado no es el mejor de los posibles, la Ley 6/2010 es el claro ejemplo de que el proceso de revisión normativa estatal, autonómico y local iniciado por la "Ley Paraguas" puede ser una buena oportunidad para reflexionar sobre la calidad de las normas de intervención ambiental y proceder a su revisión, más allá del propio ámbito de aplicación de la normativa de libre prestación de servicios.

\section{La ampliación del concepto "básico" de órgano sustantivo para integrar al órgano competente "para controlar la actividad a través de la declaración responsable o comunicación de los proyectos"}

La normativa de transposición de la Directiva de servicios sustituye un buen número de autorizaciones sectoriales exigidas a determinados proyectos por obligaciones de comunicación o declaración responsable. Los regímenes de comunicación o declaración responsable requieren de una adecuada articulación con los instrumentos de intervención urbanística y ambiental en materia de residuos, atmósfera y vertidos a las aguas marítimas y costeras. La comunicación o declaración responsable debe ir avalada por el otorgamiento o cumplimiento previo de estas exigencias de ordenación administrativa. Asimismo, algunos de estos proyectos sometidos a comunicación o declaración responsable siguen estando afectados por la obligación de evaluación de impacto ambiental. Surgen en este caso diversas preguntas ¿Quién es en ese supuesto el órgano sustantivo? ¿En qué procedimiento se integra la evaluación de impacto ambiental? La Ley 6/2010 no ha dado una respuesta idónea, a mi juicio, a estas preguntas, primado los objetivos estatales de control competencial sobre los de simplificación, integración y racionalización de procedimientos.

La nueva norma pretende contribuir a clarificar el concepto de órgano sustantivo, lo cual es fundamental para evitar la descoordinación entre administraciones y para determinar la incardinación y efectos del procedimiento accesorio de evaluación de impacto ambiental. Hasta ahora el órgano sustantivo era el competente para autorizar o aprobar el proyecto. De todas formas no todas las actividades sometidas a EIA estaban obligadas a disponer de autorización sustantiva sectorial, menos ahora tras el proceso

\footnotetext{
${ }^{7}$ RAZQUÍN LIZARRAGA, J. J., destaca que "[1]a regulación de los plazos para realizar las fases de EIA en cuanto a la Administración General del Estado resulta confusa y problemática, pues no parece necesaria la agrupación en fases, no se delimita claramente la imputación de las responsabilidades correspondientes derivadas de su incumplimiento ni son homogéneos los días de inicio y fin" ("La modificación del texto refundido..., ob. cit., p. 21)
} 
desregulador que ha desencadenado la normativa de servicios. Por tanto, algunas de lo proyectos sometidos a EIA están sometidas a un régimen sustantivo de comunicación previa, tanto en el sector servicios como en el industrial -donde el régimen de comunicación es la regla general tras el Real Decreto 2135/1980, de 26 de septiembre, de Liberalización en Materia de Instalación, Ampliación y Traslado de Industrias.

La Ley 6/2010 da una nueva definición de órgano sustantivo incluyendo al órgano de la Administración ante el que el titular del proyecto debe cumplir con la carga de presentar la correspondiente comunicación o declaración responsable:

"Órgano sustantivo: aquel órgano de la Administración pública estatal, autonómica o local competente para autorizar, para aprobar o, en su caso, para controlar la actividad a través de la declaración responsable o comunicación de los proyectos que deban someterse a evaluación de impacto ambiental.

Cuando un proyecto se vea afectado por diversos conceptos que precisen autorización, aprobación o, en su caso, control de la actividad y que se hubieren de otorgar o ejercer por distintos órganos de la Administración Pública estatal, autonómica o local, se considerará órgano sustantivo aquel que ostente las competencias sobre la actividad a cuya finalidad se orienta el proyecto, con prioridad sobre los órganos que ostentan competencias sobre actividades instrumentales o complementarias respecto a aquéllas" (art. 2.2, TRLEIAP).

El párrafo segundo del artículo 2.2 da respuesta a uno de los problemas que plantean dificultades en la práctica, la determinación del órgano sustantivo en los procedimientos sometidos a evaluación de impacto ambiental. La nueva definición dispone que el órgano sustantivo será, con carácter prioritario, el que ostente las competencias en el sector de actividad del proyecto, frente a los órganos con competencias instrumentales o complementarias, como puede ser las ambientales, sanitarias o de seguridad.

Pese a esta previsión básica podemos observar, en la legislación autonómica de intervención ambiental, que el papel de órgano sustantivo puede ser desempeñado por el órgano ambiental para la concesión de la autorización ambiental autonómica (autorización ambiental integrada u otro autorización de características similares), el órgano sectorial competente para autorizar el proyecto (o recibir la comunicación o declaración responsable) o el alcalde en el marco del procedimiento para la concesión de la licencia municipal de actividades clasificadas. Cada una de estas situaciones 
requiere de soluciones de coordinación de procedimientos diferentes que es necesario prever normativamente. La Ley 4/2009, de 14 de mayo, de protección ambiental integrada de Murcia ha realizado un esfuerzo notable en este sentido (art. 88). Esta cuestión debe ser resulta en cada ámbito autonómico con relación a los proyectos de su competencia, en atención al modelo de intervención administrativa elegido a través de las leyes marco autonómicas en esta materia.

Nada impide por tanto que las Comunidades Autónomas, con relación de proyectos de su competencia, consideren órgano sustantivo al órgano ambiental competente para autorizar instalaciones, esto es, los órganos competentes para otorgar la autorización ambiental integrada ( $\mathrm{u}$ otras autorizaciones únicas o integrales autonómicas) o la licencia municipal. La integración de la evaluación de impacto ambiental en los procedimientos ambientales indicados, unida a la supresión del mecanismo de resolución de discrepancias entre órgano sustantivo y ambiental — que ya no tendría sentido-, serían, sin duda, medidas adicionales de protección, en la medida en que refuerza la protección del interés ambiental. Con relación al resto de los proyectos -los que no son instalaciones-, el órgano sustantivo autorizatorio podría seguir siendo el órgano con competencias en el sector de actividad del proyecto. El órgano receptor de la comunicación o declaración responsable no debería desempeñar el papel de órgano sustantivo en el sentido que le otorga la normativa de evaluación de impacto ambiental. El legislador autonómico no debería otorgarle ese papel con relación a los proyectos de su competencia. Esto debería implicar la conversión del procedimiento de evaluación en un procedimiento autorizatorio donde el órgano ambiental asuma la plena capacidad decisoria, con relación a los proyectos que no sean instalaciones (ya sometidas a autorización o licencias integrales) y no estén sometidos a autorización o aprobación sustantiva. Precisaremos más adelante esta idea.

\section{La naturaleza de la DIA en el caso de proyectos sometidos a obligación} sustantiva de comunicación o declaración responsable ante la AGE

Aunque la legislación básica del Estado no haya convertido de forma expresa la declaración de impacto ambiental (en adelante DIA) en una autorización, en los supuestos de proyectos sometidos a la mera exigencia de comunicación o declaración 
responsable, es evidente que la naturaleza de ésta ya no es la de un mero acto de trámite. La DIA pasa a ser un acto que pone fin al procedimiento de evaluación de impacto ambiental, que se convierte a su vez en un procedimiento plenamente autónomo y decisorio. En estos supuestos, ante la ausencia de un procedimiento autorizatorio principal, la DIA sólo puede ser, por tanto, un acto definitivo de carácter autorizatorio que define el estatuto jurídico que rige la instalación, el funcionamiento y, en su caso, el cierre del proyecto sometido a evaluación ${ }^{8}$.

La principal consecuencia del carácter de acto definitivo de la DIA es que puede ser recurrida directamente ${ }^{9}$, en el supuesto de proyectos sometidos a comunicación o declaración responsable. Asimismo, a pesar de la previsiones del TRLEIAP, no parece que deba ser de aplicación a estos supuestos el mecanismo de resolución de discrepancias entre el órgano sustantivo y ambiental (art. 13, TRLEIAP). Ningún conflicto se puede plantear cuando sólo el órgano ambiental posee competencias para "autorizar" el proyecto y capacidad, por tanto, para definir condiciones de funcionamiento y desarrollo. El órgano sustantivo sólo tiene facultades de intervención a posteriori mediante el ejercicio de sus potestades de inspección y sanción, nunca para definir las condiciones de funcionamiento de la actividad.

\section{El órgano competente "para controlar la actividad a través de la declaración responsable o comunicación" como impulsor del procedimiento de evaluación de impacto ambiental}

Tras la modificación operada por la Ley 6/2010, el órgano competente "para controlar la actividad a través de la declaración responsable o comunicación" conserva el mismo protagonismo en la tramitación del procedimiento de EIA que el órgano sustantivo

\footnotetext{
8 En este orden de ideas, LOZANO CUTANDA considera que, en lo supuestos en los que ha se ha procedido a la eliminación de las autorizaciones sustantivas, “(...) la EIA deja de ser un acto de trámite para convertirse en el procedimiento previo de fiscalización del proyecto (lo que tiene (...) consecuencias importantes en el plano de su configuración y recursos contra la DIA)" (Derecho ambiental administrativo, La Ley, Madrid, 2010, p. 461).

9 Véase, en este mimo sentido, LOZANO CUTANDA, B., Derecho ambiental administrativo, La Ley, Madrid, 2010, p. 496.
} 
autorizatorio $^{10}$. Es el responsable, por ejemplo, de la recepción e impulso de la solicitud para la necesidad o no de sometimiento a evaluación de impacto (art. 16.1, TRLEIAP) o para la determinación del alcance del estudio de impacto ambiental (art. 6.2, TRLEIAP), y del trámite conjunto de información pública y de consulta (art. 9.1, in fine, TRLEIAP). Estas previsiones no tienen carácter básico. Con relación a los proyectos de competencia autonómica, serán las CCAA las que deban precisar su papel. Consideramos que el legislador autonómico debería eliminar la intervención en el procedimiento de EIA del órgano que recibe la comunicación o declaración responsable.

La Ley 6/2010 intenta articular la técnica preventiva de la EIA con las obligaciones de comunicación o declaración responsable previstas en la legislación sustantiva. La revisión del TRLEIAP ha sido, a este respecto, apresurada. El legislador se ha limitado a otorgar al órgano receptor de las comunicación o declaración responsable el mismo papel de impulsor del procedimiento de evaluación de impacto ambiental, que al órgano principal en el caso de los proyectos sometidos a autorización sustantiva sectorial. Ello pese a que en estos supuestos no existe un procedimiento autorizatorio principal en el que insertar la evaluación de impacto ambiental, y a que el órgano sustantivo sólo ostenta un poder de veto a posteriori sobre las actividades sometidas a comunicación o declaración responsable. Es decir, el órgano con exclusivas competencias de control ex post es el que da impulso al procedimiento preventivo de evaluación de impacto ambiental. Esta solución rompe la lógica jurídica del procedimiento de evaluación de impacto ambiental, como procedimiento accesorio que se integra en el procedimiento principal para autorizar o aprobar el proyecto. Además, este planteamiento ignora la naturaleza propia de las técnicas de control a posteriori y el papel que en el desempeñan los órganos administrativos. Teniendo en cuenta que estamos hablando de actividades liberalizadas, desde un punto de vista sustantivo, no parece razonable que el órgano receptor de la comunicación o declaración responsable deba ser el eje del desarrollo del procedimiento de EIA, y mucho menos en el supuesto de instalaciones sometidas a autorización o licencia ambiental.

10 Ello queda claramente evidenciado por la nueva Disposición adicional sexta del RDL 1/2008: "En todas las ocasiones en que el Texto Refundido se refiere al órgano de la Administración general del Estado competente para la aprobación o autorización del proyecto, se entenderá por extensión incluido el competente para controlar la actividad a través de la comunicación o declaración responsable". 


\section{La distribución de competencias ejecutivas en materia de evaluación de impacto ambiental con relación a los proyectos sometidos a la exigencia de comunicación o declaración responsable}

El artículo 4.1 del TRLEIAP dispone que “(...) el Ministerio de Medio Ambiente será órgano ambiental en relación con los proyectos que deban ser autorizados o aprobados por la Administración del Estado". Esta disposición atribuye la competencia ejecutiva al Estado en relación con los proyectos cuya autorización o aprobación sea de su competencia, de acuerdo con la legislación sustantiva aplicable (energía, hidrocarburos, energía nuclear, seguridad, etc.). La competencia sustantiva autorizatoria atrae a la competencia ambiental. Esta discutible regla de distribución competencial fue considerada constitucional por el TC en su sentencia 13/1998, recurriendo a los siguientes argumentos:

"8. El reparto competencial en esta materia [en materia ambiental] (art. 11.1 a) E.A.P.V. y art. 149.1.23.a C.E.) sólo resulta determinante respecto a aquellas intervenciones administrativas cuya razón de ser consiste en la protección del medio ambiente: es decir, cuando el acto administrativo tiene como finalidad y efecto la preservación y la restauración del ambiente afectado por la actividad intervenida, como es el caso de la autorización de actividades calificadas. Pero cuando la Administración general del Estado ejerce sus competencias exclusivas en distintos ámbitos materiales, como son administración de justicia, aeropuertos y puertos, ferrocarriles, aguas continentales, instalaciones eléctricas, obras públicas de interés general, minas y energía, patrimonio cultural y seguridad pública, hay que atenerse a la distribución de competencias que efectúan los Estatutos de Autonomía en el marco del art. 149 C.E. (y, singularmente, de los números 4, 20, $21,22,24,25,28$ y 29 del apartado 1 de ese art. 149).

Por consiguiente, es conforme con el orden constitucional de competencias que la normativa impugnada confíe la evaluación del impacto ambiental a la propia Administración que realiza o autoriza el proyecto de una obra, instalación o actividad que se encuentra sujeta a su competencia, a tenor del bloque de la constitucionalidad.

La Administración está ejerciendo sus competencias sectoriales propias cuando asegura que el organismo o la empresa que promueve la obra u otra actividad proyectada realiza el estudio de impacto ambiental; cuando somete el proyecto, y el 
estudio de impacto, a información pública; cuando realiza consultas con otras autoridades, y les pide informes; y cuando finalmente, a la vista del resultado del estudio, de las alegaciones de los particulares y de los puntos de vista de los restantes Departamentos y Administraciones públicas, formula la declaración de impacto ambiental, la cual viene a formar parte de la autorización final del proyecto.

La Administración estatal ejerce sus propias competencias sustantivas sobre la obra, la instalación o la actividad proyectada, aun cuando preceptivamente deba considerar su impacto medioambiental. No está ejecutando la legislación básica del medio ambiente. Ésta se agota en aprobar la norma que obliga a todas las Administraciones públicas a que, cuando actúan en el ejercicio de cualesquiera de sus competencias, ponderen y evalúen las repercusiones sobre el medio ambiente, minimizando y corrigiendo los daños causados a la población y al medio ambiente natural y cultural del territorio afectado por dicha actuación, cuando no enunciando a llevarla a cabo."

La Ley 6/2010 ha extendido la regla de distribución de competencia del artículo 4.1 del TRLEIAP a los casos en que un órgano de la Administración General del Estado (en adelante AGE) sea competente "para controlar la actividad a través de la comunicación o declaración responsable", por efecto de la Disposición adicional sexta del TRLEIAP introducida por la Ley 6/2010 — “En todas las ocasiones en que el Texto Refundido se refiere al órgano de la Administración general del Estado competente para la aprobación o autorización del proyecto, se entenderá por extensión incluido el competente para controlar la actividad a través de la comunicación o declaración responsable"-. El Ministerio de Medio Ambiente, Medio Rural y Marino será, por tanto, competente para realizar la EIA cuando los proyectos estén sometidos a comunicación o a declaración responsable ante un órgano de la AGE.

Como vemos la reforma legal de la EIA ha estado más guiada por el continuado ansia estatal por mantener el control de los proyectos de competencia estatal sustantiva, que por desarrollar un procedimiento de evaluación de impacto ambiental que cumpla de modo efectivo con el objetivo perseguido de prevención ambiental. La consideración del órgano competente para controlar la actividad a través de la declaración responsable o comunicación como órgano sustantivo, le permite al Estado mantener el control ambiental de la autorización de proyectos frente a las competencias ambientales autonómicas o locales. Es desde esta única perspectiva desde la que se entiende esta 
modificación, claramente distorsionadora, de la normativa de EIA. Las normas autonómicas deben huir de esta fórmula con relación a los proyectos de su competencia. No obstante, si bien los argumentos jurídicos de la sentencia 13/1998 justificaron la competencia ejecutiva estatal en materia de EIA, con relación a proyectos autorizados o aprobados por el Estado, sirven ahora, a nuestro juicio, para poner en duda la constitucionalidad de la competencia estatal ambiental con relación a los proyectos sometidos a comunicación o declaración responsable ante órganos de la AGE. En este caso la intervención preventiva es exclusivamente ambiental, sin que concurra ninguna competencia autorizatoria sectorial del Estado. Cuando se lleva a cabo la EIA de un proyecto sometido a mera comunicación, la competencia ejecutiva que se desarrolla es, a nuestro juicio, claramente ambiental. No concurre una competencia sustantiva de control previo que justifique la atracción de la competencia ambiental. Como considera la propia sentencia del Constitucional, puede entenderse que se ejerce una competencia ambiental cuando "el acto administrativo tiene como finalidad y efecto la preservación y la restauración del ambiente afectado por la actividad intervenida"; se ejerce la competencia ambiental en "aquellas intervenciones administrativas cuya razón de ser consiste en la protección del medio ambiente". En el caso de proyectos sometidos a comunicación y declaración responsable, el único acto es la declaración de impacto ambiental, en el que se evalúa exclusivamente la adecuación del proyecto a las exigencias de prevención ambiental, por lo que no puede afirmarse, con un mínimo rigor jurídico, que cuando se realiza la EIA la “(...) Administración estatal ejerce sus propias competencias sustantivas sobre la obra, la instalación o la actividad proyectada (...)".

\section{La relación temporal entre el procedimiento de evaluación de impacto ambiental y el cumplimiento de la obligación de comunicación o declaración responsable}

Como ya hemos señalado, tras la incidencia de la normativa de servicios algunos proyectos han pasado a estar sometidos, en sus respectivos sectores, a la exigencia de declaración responsable o comunicación previa. Esto ya ocurría anteriormente con relación a buena parte de las instalaciones del sector industrial, pero la legislación de EIA no daba una respuesta a estas situaciones. La Ley 25/2009 dispone que la 
evaluación de impacto ambiental tendrá que realizarse con carácter previo a la declaración responsable o comunicación previa, cuando esta sea la forma de control de la actividad (Disposición adicional quinta). Es decir la declaración responsable o comunicación previa no podrá presentarse hasta haber llevado a cabo la EIA y, en todo caso, deberá disponerse de la documentación que así lo acredite. Esta razonable previsión se refiere a los supuestos en que la obligación de impacto ambiental esté prevista tanto en la legislación básica del Estado como en la legislación autonómica de desarrollo.

El nuevo artículo 18 bis del TRLEIAP, que tiene carácter básico, ha recogido dicha regla de relación temporal con algunos matices complementarios:

"Cuando, de acuerdo con la Ley, se exija una declaración responsable o una comunicación para el acceso a una actividad o su ejercicio y una evaluación de impacto ambiental, la declaración responsable o la comunicación no podrá presentarse hasta haber llevado a cabo dicha evaluación de impacto ambiental y, en todo caso, deberá disponerse de la documentación que así lo acredite, así como de la publicación en el diario o boletín oficial correspondiente de la pertinente resolución.

Carecerá de validez y eficacia a todos los efectos la declaración responsable o la comunicación relativa a un proyecto que no se ajuste a lo determinado en la declaración de impacto ambiental o en la resolución de no sometimiento a evaluación de impacto ambiental".

La declaración responsable o la comunicación sólo podrán presentarse cuando se haya tramitado el procedimiento de EIA ${ }^{11}$, es decir, cuando se haya emitido la declaración de impacto ambiental o la resolución de no sometimiento a evaluación de impacto ambiental. Esta circunstancia debe quedar acreditada en la documentación que se adjunta a la comunicación o declaración responsable. Asimismo este artículo añade la exigencia de previa publicación de la "pertinente resolución”, es decir, de la DIA o de la resolución de no sometimiento. Al hablar de "pertinente resolución” el legislador parece darnos una pista — dudo que conscientemente — sobre el acercamiento de la DIA a la naturaleza de propia de una resolución autorizatoria.

\footnotetext{
11 Esta regla de relación temporal ha sido incorporada al art. 32.1 de la Ley 7/2006, de 22 de junio, de protección ambiental de Aragón, tras la modificación operada por el Decreto-Ley 1/2010, de 27 de abril de modificación de diversas leyes de la CA de Aragón para la transposición de la Directiva de servicios.
} 
Por otra parte, la presentación de la declaración responsable o comunicación no permitirán la puesta en marcha de la actividad, si no se cumplen las exigencias derivadas del procedimiento de EIA. Cualquier inexactitud, falsedad u omisión, de carácter esencial, en cualquier dato, manifestación o documento que se acompañe o incorpore a la comunicación, o si no se presenta la comunicación ante la autoridad competente, ello determinará la imposibilidad de continuar con el ejercicio del derecho o actividad afectada desde el momento en que se tenga constancia de tales hechos (art. 71 bis, ap. 4, Ley 30/1992). Además si ese incumplimiento queda acreditado en un momento posterior al inicio de la actividad, el órgano sustantivo y el órgano ambiental podrán suspender la actividad de acuerdo con las facultades atribuidas a la normativa sobre evaluación de impacto ambiental.

El otorgamiento al órgano receptor de las comunicación o declaración del carácter de órgano sustantivo adquiere especial significación en este sentido. La normativa de EIA atribuye al órgano sustantivo estatal "el seguimiento y vigilancia del cumplimiento de la declaración de impacto ambiental" (art. 18, TRLEIAP), así como la facultad de suspensión de la actividad "cuando se hubiere acreditado la ocultación de datos o su falseamiento o la manipulación maliciosa en el procedimiento de evaluación, siempre que hubiere influido de forma determinante en el resultado de dicha evaluación; y "cuando se hubieren incumplido o transgredido de manera significativa las condiciones ambientales impuestas para la ejecución del proyecto" (art. 22.2, letras a y b, respectivamente, TRLEIAP).

\section{La publicación de las decisiones "que se deriven de proyectos sometidos a comunicación o declaración responsable"}

No queda claro el significado del nuevo apartado 3 del artículo 15 del TRLEIAP. En él se dispone que "[1]as decisiones sobre la autorización, o aprobación de los proyectos o, en su caso, las que se deriven de proyectos sometidos a comunicación o declaración responsable de competencia de la Administración General del Estado, serán remitidas en el plazo de quince días desde su adopción por el órgano sustantivo para su posterior publicación en extracto en el Boletín Oficial del Estado”. ¿Cuáles son las decisiones que se derivan de proyectos sometidos a comunicación o declaración responsable? Cuando 
nos encontramos ante actividades sometidas a comunicación o declaración responsable, la Administración no adopta ninguna decisión previa que habilite al ejercicio de la actividad. Ese efecto lo produce el propio acto privado del particular. No hay una decisión administrativa habilitante que establezca las condiciones precisas para la puesta en funcionamiento de la actividad. Las únicas decisiones de la Administración se producen, en su caso, en el control a posteriori de la actividad, como las resoluciones administrativas que declaran la imposibilidad de continuar con la actividad de acuerdo con el artículo 71 bis. 4 de la Ley 30/1992 o que suspenden la actividad de conformidad con las previsiones de la normativa de EIA (art. 22.2, TRLEIAP). RAZQUÍN LIZARRAGA ha apuntado que "(...) lo normal en estos casos debería ser la publicidad, en extracto, de las declaraciones responsables y de la comunicación una vez producida su eficacia"12.

\section{La coordinación del procedimiento de autorización ambiental integrada con la evaluación de impacto ambiental y las técnicas de comunicación o declaración responsable}

El esfuerzo de clarificación de la tramitación del procedimiento de EIA se ha extendido al ámbito de la prevención y el control integral de la contaminación. El Real Decreto 367/2010, de 26 de marzo — relativo a la modificación de diversos reglamentos del área de medio ambiente para su adaptación a la Ley 17/2009 y a la Ley 25/2009 - ha modificado el Reglamento de desarrollo de la Ley 16/2002, de 1 de julio, de prevención y control integrado de la contaminación (en adelante LPCIC), aprobado mediante Real Decreto 509/2007, de 20 de abril (RPCIC).

La finalidad de esta modificación es clarificar la coordinación entre el procedimiento de evaluación de impacto ambiental y el de autorización ambiental integrado ${ }^{13}$, en el caso de actividades industriales del anexo I de la Ley 16/2002 sometidas también a

\footnotetext{
12 RAZQUIN LIZARRAGA, J. J., “La modificación..., ob. cit., p. 10.

13 Sobre la relación entre ambos procedimientos ambientales, véase nuestro trabajo sobre la "Integración y coordinación procedimental de la evaluación de impacto ambiental y de la autorización ambiental integrada", en NOGUEIRA LÓPEZ, A. (coordinadora), Evaluación de impacto ambiental: evolución normativo-jurisprudencial, cuestiones procedimentales y aplicación sectorial, Atelier, Barcelona, 2009.
} 
autorización sustantiva y a evaluación de impacto ambiental por la Administración general del Estado. El órgano sustantivo estatal asume el rol coordinador de los procedimientos. Recibe el estudio de impacto ambiental y gestiona el trámite conjunto de información pública, para los procedimientos sustantivo, de evaluación de impacto ambiental y de autorización ambiental integrada. Además de coordinar los procedimientos, el reglamento incluye reglas de simplificación para evitar la duplicidad documental (art. 11, RPCIC).

El RPCIC ha sido igualmente modificado para integrar los supuestos en que las industrias o instalaciones industriales están sometidas, no a autorización sustantiva, sino a la presentación de una declaración responsable o comunicación. Se aplican las mismas reglas de relación temporal de procedimientos que las previstas para el supuesto de actividades sometidas a autorización sustantiva estatal. Una vez realizado el trámite de evaluación de impacto ambiental y obtenida la autorización ambiental integrada, se presentará la declaración responsable o se realizará la comunicación adjuntando la documentación acreditativa de la declaración de impacto ambiental y de la autorización ambiental integrada (art. 13 bis).

\section{Propuesta 'de lege ferenda' para, según los casos, integrar el procedimiento de} evaluación de impacto ambiental o convertirlo en un procedimiento autónomo y decisorio en función de la diversa naturaleza de los proyectos

En materia de evaluación de impacto creo que ha faltado, a algunos efectos, diferenciar entre los proyectos de instalaciones o establecimientos y el resto de proyectos, lo cual es especialmente importante tras la expansión de los regímenes de comunicación o declaración responsable operada por la normativa de servicios. Por ello nos gustaría hacer una propuesta de lege ferenda dirigida fundamentalmente al legislador autonómico, teniendo en cuenta que poco cabe esperar de un legislador estatal más interesado en preservar parcelas competenciales que en la integración y simplificación de procedimientos.

Algunos proyectos sometidos a autorización ambiental integrada -y en algunas Comunidades Autónomas a similares autorizaciones ambientales únicas, que integran 
las autorizaciones sectoriales (residuos, atmósfera, aguas, etc.) con relación a las actividades no sometidas a control integrado- y a licencia municipal de actividades clasificadas, con informe autonómico vinculante, están sometidos igualmente a evaluación de impacto ambiental. En estos supuestos parece razonable que la legislación autonómica integre —como así han hecho varias leyes autonómicas de intervención ambiental integral - la EIA en los procedimientos para el otorgamiento de las autorizaciones o licencias ambientales. El órgano sustantivo debe ser en ese caso el órgano ambiental autonómico.

Con relación al resto de los proyectos —que no son instalaciones sometidas a autorización o licencia ambiental-, el órgano sustantivo sería el órgano sectorial competente para autorizar el proyecto. Es en este ámbito donde únicamente tiene sentido, desde mi punto de vista, el régimen de solución de discrepancias de la legislación básica del Estado (art. 13, TREIAP).

En el caso de los proyectos sometidos a declaración responsable o a comunicación - $y$ no sometidas a autorización o licencia ambiental—, no tiene sentido la figura del órgano sustantivo, por lo que no consideramos acertado atribuir este rol, tal y como lo ha hecho la legislación básica del estado (art. 2.2, TREIAP), al órgano receptor de los actos privados de comunicación. Teniendo en cuenta que ya no existe un procedimiento principal para decidir sobre la autorización del proyecto, consideramos que lo más acertado hubiera sido someter estos proyectos a “autorización de impacto ambiental”. El procedimiento de evaluación de impacto ambiental es un procedimiento accesorio que permite integrar en un procedimiento principal una variable de la que carece, la ambiental. Si la actividad está liberalizada, tiene pleno sentido que el procedimiento de evaluación adquiera también carácter decisorio y que, en consecuencia, la declaración de impacto ambiental se convierta en una resolución. En ese caso tampoco tendría lógica el instrumento de resolución de discrepancias previsto en la legislación de impacto ambiental, por lo que sólo debería mantenerse, como ya hemos señalado, con 
relación a los proyectos sometidos a autorización sustantiva y no sometidos a autorización ambiental integrada o licencia municipal ambiental ${ }^{14}$.

\section{LA REPERCUSIÓN DE LA NORMATIVA DE SERVICIOS EN LA ORDENACIÓN DE LAS ACTIVIDADES E INSTALACIONES DE GESTIÓN DE RESIDUOS}

\section{Consideraciones previas}

Las actividades de servicios en materia de "tratamiento de residuos"15 están parcialmente excluidas de la aplicación de la Directiva 2006/123 y de la "Ley Paraguas". El artículo 12 sobre "Libre prestación de servicios para los prestadores de otros Estados miembros" no es aplicable al "tratamiento de residuos", en cuanto que servicio económico de interés general ${ }^{16}$. Tampoco a la "vigilancia y control de su traslado", en la medida en que ya existe una regulación comunitaria específica ${ }^{17}$, en la que se prevén obligaciones que han de cumplirse en el país de destino o de tránsito. Nótese que esta exclusión del ámbito de aplicación de la Ley es sólo parcial. No afecta a las disposiciones de la "Ley Paraguas" sobre "libertad de establecimiento", sólo al artículo 12 sobre "libre prestación de servicio para los prestadores de otro estado miembro". Quiebra en este ámbito el principio del país de origen, que permanece latente en las previsiones de la Directiva y de la "Ley Paraguas". Los Estados miembros podrán aplicar, por tanto, a prestadores situados en otros Estados miembros las exigencias de su normativa interna, aunque en todo caso tendrán que respetar el principio de libre prestación de servicios (artículo 56, Tratado de Funcionamiento de la Unión Europea),

14 Sin embargo, en el caso de instalaciones sometidas a las Ley 16/2002, de prevención y control integrado de la contaminación, sometidas a evaluación de impacto ambiental de competencia estatal, el régimen de resolución de discrepancias mantiene pleno sentido en la medida en que no se ha procedido a la integración de la evaluación en el procedimiento de autorización ambiental integrada (art. 28, Ley 16/2002). Esto implica que el interés ambiental ve reducida su fuerza y presencia en la autorización de actividades de competencia estatal.

15 El art. 3.14 de la Directiva 2008/98/CE del Parlamento Europeo y del Consejo de 19 de noviembre de 2008 sobre los residuos y por la que se derogan determinadas Directivas, define "tratamiento" como "las operaciones de valorización o eliminación, incluida la preparación anterior a la valorización o eliminación.

${ }^{16}$ La Directiva excluye el "Tratamiento de residuos" en cuanto que servicio económico de interés general (art. 16.1, letra e).

${ }_{17}$ Reglamento (CE) 1013/2006 del Parlamento Europeo y del Consejo, de 14 de junio de 2006 , relativo a los traslados de residuos. 
por lo que la aplicación de ciertos requisitos ambientales puede no estar justificada ${ }^{18} \mathrm{O}$ ser desproporcionada.

Pese a estas exclusiones parciales del ámbito de aplicación de la normativa de servicios, la regulación de residuos estatal se ha visto afectada por las normas de transposición de la Directiva 2006/123/CE, fundamentalmente, la Ley 25/2009, de 22 de diciembre (“Ley ómnibus”), y el Reglamento 367/2010, de 26 de marzo, relativo a la modificación de diversos reglamentos del área de medio ambiente.

La Ley "ómnibus" ha alterado, en diferente medida, el régimen de las instalaciones y actividades de valorización y eliminación de residuos, y el de las actividades de gestión de residuos no peligrosos distintas de la valorización y eliminación. Por otra parte, el Real Decreto 367/2010 ha adaptado, entre otras, las normas que regulan los residuos peligrosos y los especiales ${ }^{19}$. Interesa destacar que modifica el Reglamento de residuos tóxicos y peligrosos, aprobado mediante Real Decreto 833/1988, de 20 de julio. Introduce, asimismo, previsiones sobre el Registro de Producción y Gestión de Residuos del Estado, la remisión de información, en soporte electrónico, a la Dirección general de Calidad y Evaluación Ambiental del Ministerio de Medio Ambiente, Medio Rural y Marino por las Comunidades Autónomas, y el régimen de autorización de las actividades y de las instalaciones de gestión de residuos peligrosos.

\section{El régimen de intervención administrativa en materia de gestión de residuos}

\subsection{Consideraciones generales}

El artículo 13.1 de la Ley 10/1998, de 21 de abril, de residuos (en adelante LR) ${ }^{20}$, modificado por la "Ley ómnibus", establece una autorización para las instalaciones de

\footnotetext{
${ }^{18}$ COMISIÓN EUROPEA, Manual sobre la transposición de la Directiva de servicios, 2007, p. 43.

19 La normativa sectorial modificada regula los siguientes instalaciones y residuos especiales: aparatos eléctricos y electrónicos; envases y residuos de envases; policlorobifenilos, policloroterfenilos; eliminación de depósito en vertedero; vehículos al final de su vida útil; incineración de residuos; neumáticos fuera de uso; aceites usados, pilas y acumuladores.
}

20 “1. Quedan sometidos a régimen de autorización por el órgano ambiental competente de la Comunidad Autónoma donde estén ubicadas, aquellas instalaciones donde vayan a desarrollarse actividades de valorización o eliminación de residuos.

Asimismo deberán obtener autorización las personas físicas o jurídicas que realicen actividades de valorización y eliminación de residuos previa comprobación de que las instalaciones donde se van a realizar dispongan de la autorización indicada en el párrafo anterior o bien de autorización ambiental integrada. Estas autorizaciones serán concedidas por el órgano ambiental competente de la Comunidad Autónoma donde tengan su domicilio y serán válidas para todo el territorio español. (...)". 
valorización o eliminación y otra para las personas físicas o jurídicas que desarrollan esas actividades. Como vemos, la LR prevé dos autorizaciones de naturaleza diferente. La autorización para las instalaciones de valorización o eliminación es real, ya que en su procedimiento de otorgamiento se valoran las condiciones objetivas de la obra, instalación o servicio autorizado. Mientras que la autorización de los operadores que llevan a cabo estas actividades es personal, pues para su concesión se tiene en cuenta, primordialmente, las cualidades personales del sujeto autorizado ${ }^{21}$. Esta diferente naturaleza incide en la posibilidad de transmisión, que sólo es posible en las autorizaciones reales, ya que su validez no deriva de quién sea el sujeto autorizado, sino de las condiciones en que la actividad se desarrolle. Las autorizaciones relativas a las condiciones de una instalación tienen vigencia mientras subsistan aquéllas, de donde se deduce que las alteraciones subjetivas no determinan el fin de la licencia concedida si las condiciones objetivas del establecimiento permanecen inalteradas ${ }^{22}$.

En aquellos casos en que las personas físicas o jurídicas que realicen operaciones de valorización y eliminación de residuos sean a la vez titulares de las instalaciones donde se realizan tales operaciones, el órgano ambiental competente de la Comunidad Autónoma donde esté ubicada la instalación "podrá conceder" una sola autorización que comprenda la de la instalación y la de la actividad ejercida por el titular de la misma (art. 13.1, LR). La "Ley ómnibus" introduce así en la LR una medida de simplificación e integración procedimental, que no esta prevista, sin embargo, en la propia LPCIC con relación a las actividades de gestión de residuos incluidas en su ámbito de aplicación. La autorización ambiental integrada es una licencia puramente real, que no decide sobre las cualidades personales del sujeto que gestiona la instalación.

En este mismo sentido, el Reglamento sobre residuos peligrosos, aprobado mediante Real Decreto 833/1988, ha sido modificado por el Real Decreto 367/2010. En la versión actual prevé, en primer término, una autorización a las instalaciones donde vayan a desarrollarse actividades de gestión de residuos peligrosos $\mathrm{y}$, en segundo término, otra a las personas físicas o jurídicas que realicen estas actividades, previa comprobación de que las instalaciones donde se van a

\footnotetext{
${ }^{21}$ SSTS de 27 de junio de 1994, FJ. $2^{\circ}$ (Ar. 4999); de 19 de marzo de 1997, FJ. $2^{\circ}$ (Ar. 2061).

22 ESTEVE PARDO, José, "El mercado de títulos administrativos, asignación objetiva, reasignación transparente", Estudios de derecho público económico, Libro homenaje al Prof. Dr. D. Sebastián MartínRetortillo, Civitas, Madrid, 2003, p. 755; LÓPEZ MENUDO, F., “Autorización”, Enciclopedia jurídica básica, Vol. I, ABA-COR, Civitas, Madrid, 1995, p. 75.
} 
realizar dispongan de las de la autorización indicada o de una autorización ambiental integrada. Ambas autorizaciones pueden ser otorgadas de modo integral cuando la persona que realiza las operaciones de gestión sea, a la vez, titular de la instalación donde se desarrollan tales actividades (23, RD 833/1988).

La regulación previa del artículo 13.1 de la LR preveía una única obligación de autorización para las “actividades de valorización y eliminación"23, que solo podía ser concedida "previa comprobación de las instalaciones en las que vaya a desarrollarse la actividad”. La anterior regulación no contemplaba el supuesto en el que el prestador del servicio fuera diferente del titular de la instalación donde se iba a realizar. Se preveía una única autorización para la instalación de residuos y la persona que realizaba las actividades $^{24}$.

\subsection{La vigencia temporal de las autorizaciones de valorización o eliminación y la} posibilidad de establecer límites temporales de acuerdo con la normativa de servicios

Para garantizar la libertad de establecimiento, la "Ley Paraguas" establece, con carácter general, que la realización de una comunicación o una declaración responsable o el otorgamiento de un autorización permitirán acceder una actividad de servicios y ejercerla por tiempo indefinido (art. 7.1) ${ }^{25}$. Sólo se podrá limitar la duración de la vigencia de las autorizaciones en una serie de circunstancias:

23 Con relación al texto previo a la modificación operada por la "Ley Ómnibus", SANTAMARÍA ARINAS afirma que “(...) cuando la LR habla de autorizaciones no está claro si se refiere estatuto jurídico personal del gestor de residuos, a la verificación de los requisitos reales de la instalación o a ambas cosas conjuntamente”. El autor defiende la necesidad de distinguir "(...) el régimen jurídico de ambos sistemas de autorizaciones porque atienden a finalidades diferentes" (Régimen jurídico de la producción y gestión de residuos, Monografía asociada a la Revista Aranzadi de Derecho Ambiental, núm. 11, cisura menor, 2007, p. 196).

${ }^{24}$ Lo mismo cabe decir del Reglamento de residuos peligrosos que, en la anterior versión del artículo 23.1, sometía a autorización "la realización de actividades de gestión de residuos tóxicos y peligrosos". Llama la atención que tras la modificación del reglamento de residuos no se haya procedido a la revisión de los artículos referidos al procedimiento de otorgamiento de la autorización de gestión de residuos tóxicos y peligrosos -artículo 25 (tramitación de autorizaciones), 26 (contenido del estudio ) y 27 (prestación de fianza), de modo que establezca exigencias diferenciadas para la autorización de las instalaciones de gestión de residuos peligrosos y la autorización de personas que realizan estas actividades de gestión. En su redacción actual los citados artículos aluden a la "autorización relativa al ejercicio de actividades de gestión de residuos tóxicos y peligrosos". No queda claro el procedimiento administrativo para la autorización de las personas que realizan actividades de gestión, cuando el prestador no sea titular de la instalación y la señalada autorización deba concederse de forma autónoma.

25 Las autorizaciones se concederán por tiempo ilimitado, sin perjuicio de la posibilidad de revocar las autorizaciones cuando dejen de cumplirse las condiciones que dieron lugar a la obtención de la autorización. En caso de actividades sometidas a comunicación o declaración responsable queda abierta la posibilidad a la suspensión del ejercicio de la actividad -la norma habla literalmente de "imposibilidad de continuar con el ejercicio del derecho o actividad"-, cuando se compruebe la inexactitud o falsedad de alguna información esencial que se hubiera aportado o se incumplan los requisitos de la legislación vigente (Exposición de motivos, art. 7.2, "Ley Paraguas"). 
“a) la declaración responsable o la autorización se renueve automáticamente o sólo esté sujeta al cumplimiento continuo de los requisitos;

b) el número de autorizaciones disponibles sea limitado de acuerdo con el artículo 8 de la Ley Paraguas o;

c) pueda justificarse la limitación de la duración de la autorización o de los efectos de la comunicación o la declaración responsable por la existencia de una "razón imperiosa de interés general" (art. 7.1, "Ley Paraguas").

De acuerdo con el art. 7.1, letra c, la "protección del medio ambiente" justifica las limitaciones temporales al ejercicio de actividades, como ocurre de forma habitual en el Derecho ambiental de la empresa. Es el caso, por ejemplo, de la autorización ambiental integrada — que afecta a ciertas actividades de valorización y eliminación de residuos de mayor impacto- La vigencia de la autorización ambiental integrada es de ocho años, "transcurrido el cual deberá ser renovada y, en su caso, actualizada por períodos sucesivos" (art. 25.1, Ley 16/2002). La normativa de control integrado no se ha visto afectada por la normativa de servicios. Sin embargo, ya empezamos a encontrar ejemplos de licencias o autorizaciones ambientales temporales cuya vigencia ha pasado a ser indefinida para adaptarse a las exigencias de la normativa de servicios ${ }^{26}$, lo cuál sólo parece tener justificación con relación a las actividades de menor impacto ambiental. Veamos, pues, cuál ha sido la incidencia de las limitaciones temporales de la normativa de servicios en el régimen autorizatorio de la LR.

El nuevo artículo 13.1 de la LR dispone que las autorizaciones de valorización o eliminación, tanto las de instalaciones como las de sus operadores, se concederán por un tiempo determinado, de acuerdo con las previsiones del art. 7.1, letra a, "Ley Paraguas". No se especifica ningún límite temporal, que será establecido en el propio condicionado de la autorización. En materia de residuos peligrosos -tras la modificación del Real Decreto 833/1988 operada por el Reglamento 367/2010-, las autorizaciones se otorgarán por un período de cinco años (art. 30, RD 833/1988).

Sin embargo, pasado el tiempo de concesión y de acuerdo con las previsiones del art.

\footnotetext{
26 El artículo 38 de la Ley 11/2003, de 8 de abril, de prevención de Castilla y León dispone que las "licencias ambientales" se concederán por un período de vigencia indefinido, tras la modificación operada por el Decreto-Ley 3/2009 de medidas de impulso de las actividades de servicios en Castilla y León. La regulación anterior establecía la posibilidad de que las licencias se otorgaran por un período de ocho años (redacción anterior del art. 39 1).
} 
7.1, letra a, "Ley Paraguas", las autorizaciones "se renovarán automáticamente por períodos sucesivos" (art. 13.1 in fine, Ley 10/1998). Se produce la novación automática del acto caducado por un nuevo acto administrativo que vuelve a disponer los efectos de aquél ${ }^{27}$. Se trata de autorizaciones temporales renovables automáticamente. La anterior redacción de la LR preveía que "las autorizaciones se concederán por un tiempo determinado, pasado el cual podrán ser renovadas por períodos sucesivos”. De acuerdo con la nueva redacción, la autorización no será objeto de revisión periódica obligatoria a instancia de parte. No obstante, las actividades de valorización o eliminación sometidas a control integrado dispondrán de una autorización -la autorización ambiental integradade carácter temporal y renovable periódicamente a instancia de parte.

La renovación automática de las autorizaciones no afecta a las potestades administrativas de modificación, suspensión o revocación ${ }^{28}$ de la autorización, en especial cuando dejen de cumplirse las condiciones para la concesión de la autorización (art. 7.2, "Ley Paraguas"). Por tanto, el control previo que supone la revisión periódica, a instancia de parte, se sustituye por el control a posteriori mediante el ejercicio de la potestad inspectora. En materia de residuos peligrosos el artículo 30 del RD 833/1988 tras señalar que la autorizaciones serán renovadas automáticamente, dispone que "la autoridad competente realizará las visitas de inspección que estime necesarias para comprobar que en todo momento se cumplen los requisitos para el mantenimiento de la autorización; en caso de que no fuera así se podrá suspender la autorización y se propondrán las medidas a adoptar o, en su caso, se podrá revocar la autorización”29.

\footnotetext{
27 VELASCO CABALlERO, F., Las cláusulas accesorias del acto administrativo, Tecnos, Madrid, 1996, p. 72.

${ }^{28}$ La regulación autonómica recoge esta potestad de modificación de oficio de las autorizaciones a fin de imponer medidas correctoras, de adaptar la autorización a la normativa vigente o por razones de interés público debidamente motivadas (art. 11.2, Decreto 174/2005, de 9 de junio, que regula el régimen jurídico de la producción y gestión de residuos y el Registro General de Productores y Gestores de Residuos de Galicia).

29 La propia Directiva de servicios advertía que no afecta a “(..) la posibilidad de que los Estados miembros retiren las autorizaciones a posteriori si dejan de cumplirse las condiciones necesarias para la concesión de la autorización" (considerando 55).
} 


\subsection{La validez de las autorizaciones de las personas fisicas o jurídicas que realizan} actividades de valorización o eliminación en todo el territorio nacional

De acuerdo con las previsiones generales de los artículos 4.2 y 7.3 de la "Ley Paraguas", la LR dispone que las autorizaciones de personas que realicen actividades de valorización o eliminación tendrán eficacia en todo el territorio nacional (artículo 13.1). Tal y como señala la Exposición de motivos de la "Ley Paraguas", "[c]on ello se promueve un efecto positivo para la actividad económica, por cuanto las limitaciones de la eficacia territorial de las comunicaciones, declaraciones responsables y autorizaciones, suponen una carga adicional para los prestadores que limita su movilidad geográfica".

La Exposición de motivos de la Directiva 2006/123 apunta que "[e]sta disposición -la referida a la validez nacional de las autorizaciones- no afecta a las competencias regionales o locales sobre concesión de autorizaciones en los Estados miembros" (considerando 59). Por tanto, esta previsión no priva a las Comunidades Autónomas de su competencia ejecutiva. Estas autorizaciones serán concedidas por el órgano ambiental competente de la Comunidad Autónoma donde tengan su domicilio (art. 13.1, LR). Como vemos, la validez nacional de las autorizaciones no permite al Estado imponer un régimen de autorización único a todas las CCAA en materia ambiental $^{30}$, ello supondría vaciar de contenido la competencia ejecutiva autonómica en materia ambiental.

No obstante, las Comunidades Autónomas que establezcan normas adicionales de protección para el acceso a la prestación de servicios de valorización y gestión de residuos, tendrán que asumir en su territorio el desarrollo de actividades que no se adecuan a sus estándares ambientales más proteccionistas. Ello puede implicar la igualación a la baja de los niveles de exigencia ambiental para las actividades de los operadores de gestión de residuos, efecto que puede ser enervado por la legislación básica estatal de mayor densidad en esta materia. Con todo, la validez nacional de las

\footnotetext{
30 Véase sobre esta cuestión PADRÓS REIG, C., "La competència autonòmica ejecutiva sobre el regime administratiu de les activitats d'inspecció tècnica", El Clip, Institut d'Estudis Autonòmics, núm. 40, 2007. En un sentido crítico con la competencia estatal para la imposición de un régimen administrativo único, GARRIDO CUENCA, N. M., ORTEGA ÁLVAREZ, L., "Legislación básica: el impacto ambiental de la Directiva de servicios", Observatorio de Políticas Ambientales 2010, Aranzadi, 2010, p. 187.
} 
autorizaciones no parece adecuarse al reparto competencial entre el Estado y la $\mathrm{CA}^{31}$. La competencia estatal para desarrollar legislación básica ambiental no puede restringir la capacidad de las CA para exigir mayores niveles de protección en su ámbito autonómico.

Sin embargo, la "Ley Paraguas" prevé un excepción a la regla general de la validez nacional de las autorizaciones: “(...) las administraciones públicas podrán otorgar autorizaciones (...) a los prestadores cuya eficacia esté limitada a una parte específica del territorio cuando esté justificado por razones de (...) protección del medio ambiente, resulte proporcionado y no discriminatorio y de forma suficientemente motivada" (art. 7.3, parr. $2^{\circ}$ ). La "Ley ómnibus" no se ha acogido a esta posibilidad con relación a la autorización de personas que realicen actividades de valorización y eliminación de residuos, reconociendo que esta autorización tendrá efecto en todo el territorio nacional. El legislador estatal no ha considerado proporcionada esta limitación, es decir, ha entendido que esa medida no era idónea para la protección del medio ambiente o que se trataba de la opción menos restrictiva para alcanzar el objetivo ambiental prevista. Se trata de una valoración cuando menos discutible, si tenemos en cuenta que ello imposibilita la exigencia en el ámbito autonómico de mayores niveles de protección. La normativa de residuos no prejuzga el objetivo ambiental, ni establece límites en este sentido, simplemente exige que una vez definido éste la medida destinada a alcanzarlo sea útil y lo menos restrictiva posible para conseguir el fin previsto. La opción del legislador estatal en materia de residuos restringe sin duda la posibilidad de hacer efectivos niveles de protección más exigentes en el ámbito autonómico.

La legislación básica de residuos podría haber establecido una limitación territorial en esta materia. En ese caso, las nuevas posibilidades de cooperación intercomunitaria abiertas por los nuevos estatutos de autonomía, como los convenios de reconocimiento

\footnotetext{
31 Véase en este orden de cosas GARRIDO CUENCA, N. M., ORTEGA ÁlVAREZ, L., "Legislación básica..., ob. cit., p. 186.
} 
mutuo de licencias entre Comunidades Autónomas ${ }^{32}$, podrían ofrecer una vía para dotar de eficacia extraterritorial a las títulos habilitantes autonómicos para el ejercicio de estas actividades de servicios ${ }^{33}$, garantizando a un mismo tiempo las competencias autonómicas, legislativas y ejecutivas, en materia ambiental y, en consecuencia, los niveles de protección ambiental fijados por cada $\mathrm{CCAA}^{34}$.

Por otra parte, la legislación básica de residuos quizás podría haber adoptado una opción más creativa, permitiendo a los operadores autorizados por una Comunidad Autónoma desarrollar su actividad en otra, garantizando, en todo caso, el cumplimiento de las normas adicionales de protección establecidas por cada Comunidad Autónoma, mediante la exigencia, por ejemplo, de comunicación previa, que ponga en conocimiento de las autoridades la resolución autorizatoria - emitida por otra Comunidad Autónoma - y en la que se acredite, en su caso, el cumplimiento de las exigencias adicionales de protección previstas en la legislación autonómica

32 Véase, como ejemplo, el Convenio de colaboración entre Comunidades Autónomas para el reconocimiento recíproco de las licencias de caza y de pesca recreativa en aguas interiores, firmado por las Comunidades Autónomas de Castilla y León, Andalucía, Aragón, Cataluña, Valenciana e Illes Balears (Boletín Oficial de las Cortes Generales, Senado, Serie I, núm. 356, 12 de noviembre de 2009). Interesa destacar los motivos justificativos de la adopción del acuerdo: "El reconocimiento recíproco de licencias de caza y de pesca recreativa y la coordinación de unos criterios de convergencia evitará que pescadores y cazadores se vean obligados a repetir los mismos trámites y gestiones administrativas en cada una de las Comunidades Autónomas donde deseen cazar o pescar, y a su vez, las distintas Administraciones Autonómicas ahorrarán esfuerzos y gastos, lográndose así una gestión más eficiente de los recursos públicos".

33 En este sentido, NOGUEIRA LÓPEZ propone, con relación a las entidades colaboradoras de la administración, "un régimen de homologación o reconocimiento que permita contrastar el cumplimiento de aquellos requisitos propios que se derivan de la legislación autonómica sin necesidad de emprender un procedimiento complejo de acreditación". "Esta probablemente sería -a juicio de la autora- la vía más correcta de suplementar las exigencias específicas de cada régimen administrativo autonómico específico sin introducir cargas desproporcionadas -que podrían entenderse contrarias al principio de libre prestación de servicios" ("Público y privado en el control operativo de actividades de servicios: un nuevo campo para la entidades colaboradoras de la Administración", comunicación presentada en el V Congreso de la Asociación española de Profesores de Derecho Administrativo, 2010, p. 13)

\footnotetext{
${ }^{34}$ Interesa destacar que en el marco del Convenio de colaboración entre Comunidades Autónomas para el reconocimiento recíproco de las licencias de caza y de pesca recreativa en aguas interiores -señalado en la nota 102-, se prevé la creación de una Comisión Sectorial de Desarrollo y Seguimiento para dar cumplimiento al convenio. Este órgano tiene como finalidad desarrollar los criterios de convergencia entre las diferentes CCAA firmantes, relativos a las condiciones de aptitud, a la duración de las licencias y los requisitos administrativos. Este mecanismo puede permitir una igualación al alza de los diferentes niveles de protección ambiental previsto en la legislación autonómica.
} 
correspondiente ${ }^{35}$. Con todo, esta solución nos plantea dudas en términos competenciales. La obligación de comunicación (para las actividades autorizadas en otras CCAA) puede no ser suficiente, en todos los casos, para alcanzar el objetivo ambiental marcado por la Comunidad Autónoma. El nivel de protección ambiental pretendido puede hacer necesario y proporcionado el sometimiento de estas actividades a un régimen de autorización de validez territorial limitada a la Comunidad Autónoma.

La "Ley Paraguas" dispone que "podrá exigirse una autorización, una comunicación o una declaración responsable individual, para cada establecimiento físico, cuando esté justificado por una razón imperiosa de interés general, resulte proporcionado y no discriminatorio" (art. 7.3, parr. $3^{\circ}$ ). La propia Exposición de motivos de la Directiva 2006/123 afirma que “(...) la protección del medio ambiente justifica que se exija una autorización individual para cada instalación física en el territorio nacional" (considerando 59). La necesidad de un evaluación individual de cada instalación justifica la limitación territorial ${ }^{36}$. Los órganos autorizatorios deben evaluar en el procedimiento no sólo la naturaleza y características técnicas de la actividad, sino también su incidencia ambiental en atención a las condiciones locales del medio ambiente, lo cuál hace preciso una valoración caso por caso, aun en el caso de que nos encontremos con instalación idénticas. Esta es una de las razones por la que la normativa de servicios no ha afectado, de forma relevante, a las normas reguladoras de la instalación de actividades con repercusiones sobre el medio ambiente (control integrado de la contaminación, atmósfera, grandes instalaciones de combustión, incineración de residuos, etc.).

Por todo ello, la LR, tras la modificación de la "Ley ómnibus", exije una autorización individual para cada instalación de valorización o eliminación de residuos, lo cual está claramente justificado por la necesidad de proteger el medio ambiente como razón

\footnotetext{
${ }^{35}$ En este sentido, interesa destacar el artículo 3.3 del Real Decreto 1315/2005, de 4 de noviembre, por el que se establecen las bases de los sistemas de seguimiento y verificación de emisiones de gases de efecto invernadero en las instalaciones incluidas en el ámbito de aplicación de la Ley 1/2005, de 9 de marzo, por la que se regula el régimen del comercio de derechos de emisión de gases de efecto invernadero: “(...) un verificador acreditado en una comunidad autónoma podrá realizar tareas de verificación en el territorio de otra comunidad autónoma distinta, siempre que comunique su intención al órgano autonómico competente en el territorio donde desee actuar con una antelación mínima de un mes y aporte la documentación que acredite que dispone de una acreditación en vigor emitida con respecto a los criterios y requisitos establecidos en este real decreto".
}

${ }^{36}$ COMISIÓN EUROPEA, Manual sobre la transposición de la Directiva de servicios, 2007, p. 28. 
imperiosa de interés general. Estas autorizaciones, como es razonable, no dan la posibilidad de desarrollar instalaciones de este tipo en otra parte del territorio nacional. La apertura de un nuevo "establecimiento físico"37 en otra parte del territorio nacional implica la necesidad de una nueva autorización de instalación. La "Ley Paraguas" dispone además que "[c]uando el prestador de servicios ya esté establecido en España y ejerza legalmente la actividad, estas autorizaciones o declaraciones responsables no podrán contemplar requisitos que no estén ligados específicamente al establecimiento físico a partir del cual pretende llevar a cabo dicha actividad" (art. 7.3, in fine). Parece deducirse de esta previsión que la autorización de instalaciones de valorización o eliminación no podrá contener, en su condicionado, exigencias subjetivas que limiten el ejercicio de la actividad del prestador de servicios de gestión, cuando este ya haya obtenido la correspondiente autorización personal de valorización o eliminación de residuos en otra CA.

\subsection{La exigencia de comunicación previa a los gestores de residuos no peligrosos}

Tras la "Ley Ómnibus", los titulares de las actividades en las que se desarrollan operaciones de gestión de residuos no peligrosos, distintas de la valorización o eliminación, se someten al régimen de la comunicación previa —exigencia que también afecta a los transportistas de residuos peligrosos cuando actúan como meros intermediarios por cuenta de tercero, de acuerdo con el artículo 22.1 de la LR-, ante el órgano ambiental competente de la Comunidad Autónoma donde tengan su sede (art. $15, \mathrm{LR})^{38}$.

En realidad esta obligación ya existía, con algún matiz, en la versión anterior a la modificación operada por la "Ley Ómnibus". En ella se decía que los titulares de las actividades "deberán notificarlo", mientras que ahora "deberán comunicarlo". El proceso de revisión está sirviendo para desterrar de nuestro ordenamiento el uso del término "notificación" para aludir a la comunicación previa. Este error se deriva de las

\footnotetext{
37 El concepto de establecimiento físico es definido por la "Ley Paraguas" como "cualquier infraestructura estable a partir de la cual se lleva a cabo efectivamente una prestación de servicios" (artículo 3.6).

${ }^{38}$ Esta información será inscrita por la CA en el "Registro de Producción y Gestión de Residuos" (art. 15, Ley 10/1998).
} 
traducciones literales del término inglés 'notification' de las versiones originales de las Directivas comunitarias. En nuestra cultura jurídica, la notificación es el acto de comunicación por el se que pone en conocimiento de una persona (el interesado y todos los que intervienen en el procedimiento) un acto administrativo anterior ${ }^{39}$. Nada tiene que ver con el concepto de comunicación, que es “(...) aquel documento mediante el que los interesados ponen en conocimiento de la Administración Pública competente sus datos identificativos y demás requisitos exigibles para el ejercicio de un derecho o el inicio de una actividad(...)" (artículo 71 bis.2, Ley 30/1992)

Hay un ánimo de generalización de la comunicación previa como técnica de ordenación administrativa de las actividades de gestión de residuos no peligrosos. Esto queda evidenciado por el hecho de que se retira del artículo 15 de la LR la referencia a la posibilidad de que las CCAA sometan a autorización estas actividades de gestión de residuos no peligrosos ${ }^{41}$. No obstante, esta posibilidad quedaría abierta siempre que esté justificada por razones de protección del medio ambiente, y sea proporcionada y no discriminatoria, en virtud de la competencia autonómica para aprobar normas adicionales de protección.

\subsection{La conversión de las obligaciones de inscripción de los gestores de residuos en} deberes de registro de oficio por parte de los órganos administrativos. La creación del nuevo "Registro de Producción y Gestión de Residuos del Estado"

En el Derecho autonómico, por ejemplo en Galicia, las personas físicas y jurídicas que realizan actividades de gestión de residuos están sometidas a la obligación de

39 GONZÁlEZ PÉREZ, J., GONZÁlEZ NAVARRO, F., Comentarios a la Ley de régimen jurídico de las Administraciones públicas y procedimiento administrativo común, Tomo I, 4a edición, 2007, pp. 1668 y 1669.

40 En este mismo sentido, la "Ley Ómnibus" ofrece una nueva redacción del artículo 10, referido a la importación, adquisición intracomunitaria, intermediación y agencia. Los sujetos que realicen estas actividades - "los importadores y adquirentes intracomunitarios, así como los agentes comerciales o intermediarios que, en nombre propio o ajeno, pongan residuos en el mercado o realicen operaciones jurídicas que impliquen cambio de titularidad posesoria"-, "deberán comunicar el inicio de sus actividades" al órgano ambiental de la Comunidad autónoma "donde tengan su domicilio". Más en concreto, deben de comunicar "las cantidades, naturaleza, orígenes y destinos de los mismos, así como en su caso el método de transporte y el método de valorización o eliminación que se vaya a emplear" (art. 10, Ley 10/1998). La anterior redacción de este artículo sólo preveía una obligación de "notificación" reiteramos aquí las mismas reflexiones previas sobre esta terminología jurídica- al órgano ambiental de la CA donde los sujetos afectados "realicen sus actividades".

41 Lo mismo ocurre en el artículo 10 con relación a las actividades de importación, adquisición intracomunitaria, intermediación y agencia. 
inscripción en el Registro General de Productores y Gestores de Residuos de Galicia ${ }^{42}$. Esta obligación de registro la encontramos en otras normas autonómicas.

Estas previsiones autonómicas no son compatibles con la "Ley Paraguas". La existencia de obligaciones autorizatorias o de comunicación en la LR hace desproporcionada la exigencia de inscripción, a instancia de parte, en un registro de gestores de residuos. "Las Administraciones públicas no podrán exigir requisitos, controles previos o garantías equivalentes o comparables, por su finalidad a aquellos a los que ya esté sometido el prestador en España o en otro Estado miembro" (art. 9.1, "Ley Paraguas").

Tras las modificaciones normativas de la legislación de residuos, a nivel tanto legal como reglamentario, las obligaciones de registro e inscripción de los gestores de residuos se convierten en deberes de información y comunicación entre Administraciones públicas. Así los órganos ambientales de las Comunidades Autónomas tienen que inscribir de oficio en el nuevo Registro de Producción y Gestión de Residuos del Estado, todas las informaciones, documentos y actos que se deriven de la aplicación de la legislación de residuos.

La "Ley ómnibus" modifica la Ley de residuos para crear un Registro de Producción y Gestión de Residuos del Estado (art. 6 bis, LRl). Las Comunidades Autónomas incorporarán a este registro, a efectos informativos, todo la información, autorizaciones y registros que se deriven de esta Ley. El Real Decreto 367/2010 ha integrado y concretado estás obligaciones informativas de la CA mediante la modificación de los reglamentos de residuos peligrosos ${ }^{43}$, de envases y residuos de envases ${ }^{44}$, de eliminación y gestión de policlorobifenilos, policloroterfenilos y aparatos que los contengan ${ }^{45}$, de eliminación de residuos en vertedero ${ }^{46}$, de gestión de vehículos al final

\footnotetext{
42 Véase los artículos 27 y ss. del Decreto 174/2005, de 9 de junio, que regula el régimen jurídico de la producción y gestión de residuos y el Registro General de Productores y Gestores de Residuos de Galicia.

${ }^{43}$ Las autorizaciones derivadas del RD 833/1988 se inscribirán por la CA en el Registro de Producción y Gestión de Residuos (art. 9.2).

${ }^{44}$ Las autorizaciones de sistemas integrados de gestión de residuos de envases se inscribirán por la CA en el Registro (art. 8.4, RD 782/1998).

${ }^{45}$ La regulación de este tipo de residuos obliga a las CA a inscribir las autorizaciones de las empresas de recogida, descontaminación y eliminación de PCB y aparatos que los contengan (art. 11.1, RD 1378/1999).

46 Su normativa establece la obligación de inscripción por la CA de las autorizaciones de estas actividades (art. 7, RD 1481/2001).
} 
de su vida útil ${ }^{47}$, de incineración de residuos $^{48}$, de residuos de aparatos eléctricos y electrónicos ${ }^{49}$, de gestión de neumáticos fuera de uso $^{50}$, de gestión de aceites usados ${ }^{51}$, de pilas y acumuladores y la gestión ambiental de sus residuos ${ }^{52}$.

Este registro será "compartido y único para todo el territorio español". La validez para todo el territorio nacional de las autorizaciones de las actividades de valorización y eliminación exige por tanto de la disposición de un registro común que integre toda la información derivada de la aplicación de la legislación de residuos. Se trata de una medida adecuada de coordinación administrativa. No obstante, se plantean aquí algunas cuestiones, como su compatibilidad con los eventuales registros autonómicos. Nada parece que se oponga a la existencia de un registro autonómico interno de seguimiento de la información derivada de la aplicación de las técnicas de policía administrativa, previstas en la legislación de residuos, siempre que no suponga la exigencia de obligaciones de registro para actividades ya sometidas a autorización o comunicación previa. Habría que plantearse sin embargo su necesidad, en términos de organización interna de la Administración ambiental o de creación de un instrumento de difusión de información ambiental, ante la existencia de un registro centralizado como el que plantea el artículo 6 bis.

Otra cuestión es si esta previsión es compatible con la competencia autonómica de gestión ambiental. El interés suprautonómico en disponer de información compartida, fiable y coordinada sobre la gestión de residuos, la necesidad de realizar un control efectivo y coordinado de las actividades de valorización y eliminación de residuos, con autorizaciones válidas para todo el territorio, la consulta a las Comunidades Autónomas

\footnotetext{
${ }^{47}$ Las CA están obligación a inscribir las autorizaciones de los sistemas integrados de gestión de este tipo de residuos (art. 7.1, RD 1383/2002).

${ }^{48}$ Las CA tienen que inscribir las autorizaciones de incineración de residuos (art. 4.5, RD 653/2003).

${ }^{49}$ Las CA deberán inscribir las autorizaciones de instalaciones de recogida y tratamiento de estos residuos (art. 6.3, RD 208/2005, de 25 de febrero), así como las autorizaciones de sistemas integrados de gestión (art. 8.2, RD 208/2005, de 25 de febrero).

${ }^{50}$ Las comunicaciones de los titulares de las actividades de gestión de neumáticos fuera de uso, distintas de la valorización o eliminación (art. 6.1, RD 1619/2005), así como las autorizaciones de los sistemas integrados de gestión de neumáticos (art. 8.2, RD 1619/2005), deberán ser registradas por las CA.

51 Obligación de inscripción de los productores de aceites usados y de las autorizaciones de los sistemas integrados de gestión en el Registro por las CA (arts. 5.3, 12.1, RD 679/2006).

52 Las CCAA deben inscribir en el registro las autorizaciones y "acuerdo voluntarios" previstos en el RD 106/2008, de 1 de febrero, sobre pilas y acumuladores y la gestión ambiental de sus residuos (arts. 3 bis, 20.1, RD 106/2008).
} 
en el proceso de desarrollo reglamentario del Registro, la exigencia de acuerdo entre Estado y CCAA en la determinación del contenido de algunas inscripciones ${ }^{53}$ y su intervención directa en la gestión del registro único — las Comunidades Autónomas incorporan al Registro la información, las autorizaciones y registros que se deriven de la LR - apoyan, desde mi punto de vista, la constitucionalidad y la racionalidad de la medida.

Queda pendiente su desarrollo reglamentario que debe llevarse a cabo previa consulta de las CCAA. Este registro será público y accesible a cualquier persona física o jurídica "que cumpla con los requisitos que reglamentariamente se establezcan". Como es evidente, su desarrollo reglamentario no podrá establecer restricciones más allá de lo previsto en la Ley 27/2006, de 18 de julio, que regula los derechos de acceso a la información, de participación pública y de acceso a la justicia en materia de medio ambiente.

\footnotetext{
${ }^{53} \mathrm{El}$ contenido de las inscripciones específicas en el registro se determinará de acuerdo con las CCAA. Esta previsión la encontramos en los artículos 7 RD 1481/2001 por el que se regula la eliminación de residuos mediante depósito en vertedero; 7.1 del RD 1383/2002 sobre gestión de vehículos al final de su vida útil; y 4.5 del RD 653/2003 de incineración de residuos.
} 


\section{BIBLIOGRAFÍA}

COMISIÓN EUROPEA, Manual sobre la transposición de la Directiva de servicios, 2007.

ESTEVE PARDO, José, "El mercado de títulos administrativos, asignación objetiva, reasignación transparente", Estudios de derecho público económico, Libro homenaje al Prof. Dr. D. Sebastián Martín-Retortillo, Civitas, Madrid, 2003.

GARRIDO CUENCA, Nuria María, ORTEGA ÁLVAREZ, Luis, “Legislación básica: el impacto ambiental de la Directiva de servicios", Observatorio de Políticas Ambientales 2010, Aranzadi, 2010.

GONZÁlEZ PÉREZ, Jesús, GONZÁLEZ NAVARRO, Francisco, Comentarios a la Ley de régimen jurídico de las Administraciones públicas y procedimiento administrativo común, Tomo I, 4ª edición, Civitas, 2007.

LÓPEZ MENUDO, Francisco, “Autorización”, Enciclopedia jurídica básica, Vol. I, ABA-COR, Civitas, Madrid, 1995.

LOZANO CUTANDA, Blanca, Derecho ambiental administrativo, La Ley, Madrid, 2010 .

MINISTERIO DE ECONOMÍA Y HACIENDA, Informe sobre la transposición de la Directiva de servicios, 29 de abril de 2010.

MUÑOZ MACHADO, "Ilusiones y conflictos derivados de la Directiva de servicios", Revista General de Derecho Administrativo, núm. 21, 2009.

NOGUEIRA LÓPEZ, Alba (coordinadora), Evaluación de impacto ambiental: evolución normativo-jurisprudencial, cuestiones procedimentales y aplicación sectorial, Atelier, Barcelona, 2009.

NOGUEIRA LÓPEZ, Alba, "Público y privado en el control operativo de actividades de servicios: un nuevo campo para la entidades colaboradoras de la Administración", comunicación presentada en el V Congreso de la Asociación española de Profesores de Derecho Administrativo, 2010. 
PADRÓS REIG, Carlos, "La competència autonòmica ejecutiva sobre el regime administratiu de les activitats d'inspecció tècnica", El Clip, Institut d'Estudis Autonòmics, núm. 40, 2007.

PERNAS GARCÍA, J. José, "Integración y coordinación procedimental de la evaluación de impacto ambiental y de la autorización ambiental integrada", en NOGUEIRA LÓPEZ, Alba (coordinadora), Evaluación de impacto ambiental: evolución normativo-jurisprudencial, cuestiones procedimentales y aplicación sectorial, Atelier, Barcelona, 2009.

— "La incidencia de la normativa de servicios en el Derecho ambiental", versión escrita y extendida de la ponencia pronunciada en el Seminario Internacional sobre Prestación de Servizos e Dereito, dirigido por la profesora Alba Nogueria López y celebrado los días 4 y 5 de octubre (pendiente de publicación).

RAZQUIN LIZARRAGA, José Joaquín, "La modificación del texto refundido de la Ley de evaluación de impacto ambiental de proyectos por la Ley 6/2010, de 24 de marzo", Revista Catalana de Dret Ambiental, vol. I, núm. 1, 2010.

SANTAMARÍA ARINAS, René Javier, Régimen jurídico de la producción y gestión de residuos, Monografía asociada a la Revista Aranzadi de Derecho Ambiental, núm. 11, cisura menor, 2007.

VELASCO CABALLERO, Francisco.: Las cláusulas accesorias del acto administrativo, Tecnos, Madrid, 1996. 